\title{
Martin Heckel, Martin Luthers Reformation und das
} Recht

\section{Gérald Chaix}

\section{OpenEdition}

Journals

Édition électronique

URL : http://journals.openedition.org/ifha/9212

DOI : 10.4000/ifha.9212

ISSN : 2198-8943

\section{Éditeur}

IFRA - Institut franco-allemand (sciences historiques et sociales)

\section{Référence électronique}

Gérald Chaix, « Martin Heckel, Martin Luthers Reformation und das Recht », Revue de l'IFHA [En ligne], Date de recension, mis en ligne le 20 juin 2018, consulté le 24 septembre 2020. URL : http:// journals.openedition.org/ifha/9212 ; DOI : https://doi.org/10.4000/ifha.9212

Ce document a été généré automatiquement le 24 septembre 2020

(C)IFHA 


\title{
Martin Heckel, Martin Luthers Reformation und das Recht
}

\author{
Gérald Chaix
}

\section{RÉFÉRENCE}

Martin Heckel, Martin Luthers Reformation und das Recht. Die Entwicklung der Theologie Luthers und ihre Auswirkung auf des Recht unter den Rahmenbedingungen der Reichsreform und der Territorialstaatsbildung im Kampf mit Rom und den "Schwärmen", Tübingen: Mohr Siebeck (Jus ecclesiasticum 114), 2016, 988 p., $69 €$ 
La présente note ne peut pas pleinement rendre compte de la « somme » qu'a livrée le spécialiste de l'influence de la Réformation sur le droit et sur la pensée politique. D'apparence quelque peu austère, l'ouvrage est néanmoins d'utilisation aisée grâce à son index des matières extrêmement détaillé et intégrant la mention des écrits de Luther spécifiquement mentionnés. Il permet ainsi de retrouver une information solidement fondée ainsi qu'une bibliographie détaillée. C'est sans doute cette utilisation, ponctuelle mais régulière, qui prévaudra. D'autant que c'est toute l'histoire de la Réformation qui est en réalité revisitée.

Martin Heckel étudie le droit progressivement reconnu aux confessions

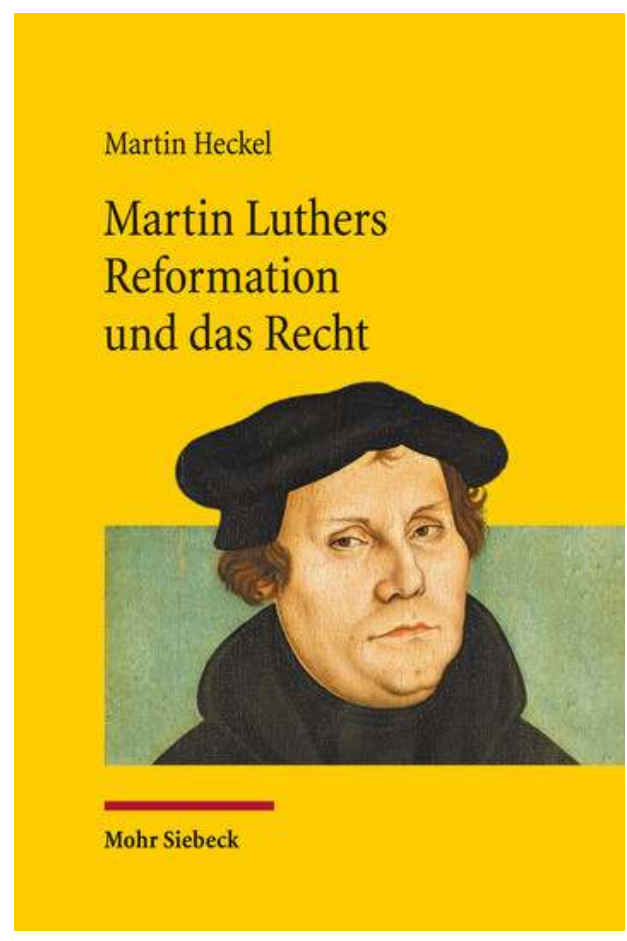
ainsi que les procédures mises en place de manière originale et efficace à la chambre de justice impériale (Reichskammergericht), de manière plus complexe et parfois inhibitive à la Diète (Reichstag) - afin d'assurer la paix sur une base juridique. Il présente de manière détaillée et nuancée le "droit de résistance ", qui ne cesse d'évoluer tout au long du XVI ${ }^{\mathrm{e}}$ siècle et dont les rapports avec le droit naturel, le droit public ou encore le droit féodal peuvent varier selon les auteurs. Il pose l'importante question du rapport entre le droit et la vérité. Il étudie le processus de sécularisation qui découle de la «judiciarisation" inhérente au processus de "pacification religieuse ». Il étudie la place des courants marginaux (Schwärmer, Täufer, Antitrinitariens, Spirituels) qui ne bénéficient pas d'une reconnaissance juridique. Il analyse le recours croissant à la notion de droit naturel et observe la relation dialectique que celui-ci entretient avec le Sermon sur la montagne (Bergpredigt), au centre de la pensée de Luther notamment. La question de la lutte armée contre les Turcs est évoquée, celle de l'attitude de Luther à l'égard des Juifs, qualifiée d'antisémite mais distinguée de l'antisémitisme racial des XIX et XXe siècles, longuement examinée. La théorie des deux règnes (Zwei-Reiche-Lehre) fait évidemment l'objet de multiples développements au-delà du chapitre qui lui est spécifiquement consacré. C'est ainsi un véritable dictionnaire de la pensée de Luther et du luthéranisme qui est mis à disposition. 
INDEX

Index chronologique : Période moderne

Thèmes : Histoire religieuse ; Histoire des mentalités

\section{AUTEURS}

\section{GÉRALD CHAIX}

Université de Tours, UMR 7323 